\title{
Effects of Alloy Content on Impact Toughness in X80 Pipeline Steel
}

\author{
Guoxi WU', ${ }^{1,}$, Chengjun $\mathrm{LIU}^{1, \text { a }}$, Ren $\mathrm{CHEN}^{2, \mathrm{~b}}$, Xiaoliang $\mathrm{LI}^{2}$ and Maofa JIANG ${ }^{1}$ \\ ${ }^{1}$ School of Materials and Metallurgy, Northeastern University, Shenyang, China \\ ${ }^{2}$ School of Metallurgical Engineering, Liaoning Institute of Science and Technology, Benxi, China

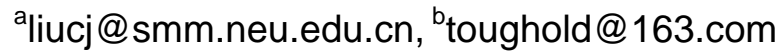

Keywords: pipeline steel, alloying element, impact toughness.

Abstract. The X80 pipeline steel for the west to east gas transmission project was successful produced, based on the hot strip mills equipment advantage. However, the impact toughness was unstable during the production. In this research, optical microscope, scanning electron microscopy (SEM) and energy dispersive analysis (EDS) test were used to study the relationships between different alloy content and microstructure in pipeline steel. What's more, the effect of alloy content on impact toughness in X80 pipeline steel has been explored based on the statistics of alloy composition and the performances in production. The results show that, the alloying elements in X80 pipeline steel can be divided into three categories in this condition. First, $\mathrm{Ni}, \mathrm{Cu}$ and $\mathrm{Mo}$ alloy, it promotes the MA constituents transformation, and leading the impact toughness decreases. Second, $\mathrm{Cr}$ and $\mathrm{Mn}$ alloy, which have no significant effect on impact toughness. And the third, $\mathrm{Nb}$ and $\mathrm{Ti}$ micro-alloying, which is particularly improving the impact toughness in pipeline steel.

\section{Introduction}

High strength and high toughness pipeline steels make great contributions to energy conservation and cost reduction as well as to increased transportation efficiency of crude oil and natural gas. It is widely acknowledged that natural gas is the most important source of the energy in nowadays. The demand of the energy increasing significantly in eastern of China, but most of the natural gas is produced in western region. So the west to east gas transmission project has been started since 15 years ago. To reduce the construction costs, the third-line project of west to east gas transmission project used the 0.8 design factor. Besides, the project also under severe conditions of higher pressures and low temperatures, it can be abruptly fractured when cracks initiate and propagate rapidly by impact, explosion, or earthquake. Therefore, the performance of pipeline steel plate put forward higher requirements, especially for impact toughness [1-3].

Based of the advanced hot rolling mill, the company successfully developed and manufactured the X80 pipeline steel for the third-line project of west to east gas transmission project. In order to accord the high toughness requirements, the alloying elements $\mathrm{Mo}, \mathrm{Ni}, \mathrm{Cu}, \mathrm{Cr}, \mathrm{Nb}, \mathrm{V}$ and $\mathrm{Ti}$, et al. have been employed, combining with TMCP process. However, it shows that the strength is relatively stable, but the impact toughness fluctuations. Therefore, the differences of impact toughness were analyzed in this study, combined the composition and properties of X80 pipeline steel statistics. And this research also can provide the necessary theoretical support for optimizes the design and development of X80 pipeline and higher grade pipeline steel.

\section{Experimental}

The requirements of the project using engineering design factor 0.8 standard are as follows: yield strength $555 \sim 690 \mathrm{MPa}$, tensile strength $625 \sim 825 \mathrm{MPa}$, Charpy impact toughness $\left(-20^{\circ} \mathrm{C}\right) \geq 280 \mathrm{~J}$. Thus, the X80 pipeline steel design component is shown in Table 1.

The X80 pipeline steels were prepared by 150t converter, LF and RH refining process was also used. And then, the continuous casting slab for thick plates with dimensions $230 \mathrm{~mm} \times 1500 \mathrm{~mm}$, reheated to $1200^{\circ} \mathrm{C}$, and followed by $3 \mathrm{~h}$ holding time. Finally, fabricated and rolled for thick plates with dimensions $16.5 \mathrm{~mm} \times 1550 \mathrm{~mm}$ by TMCP process, the cooling rate of $40^{\circ} \mathrm{C} / \mathrm{s}$. The strength and toughness and other mechanical properties were measured after warehousing $8 \mathrm{~h}$ later. 
Table 1 Chemical composition of X80 pipeline steel, $\mathrm{wt} \%$

\begin{tabular}{ccccccccc}
\hline $\mathrm{C}$ & $\mathrm{Si}$ & $\mathrm{Mn}$ & $\mathrm{Cu}$ & $\mathrm{Ni}$ & $\mathrm{Cr}$ & $\mathrm{Mo}$ & $\mathrm{Nb}$ & $\mathrm{V}$ \\
\hline $0.06 \sim 0.07$ & $0.2 \sim 0.3$ & $1.75 \sim 1.85$ & $0.25 \sim 0.35$ & $0.25 \sim 0.35$ & $0.20 \sim 0.30$ & $0.25 \sim 0.35$ & $0.10 \sim 0.15$ \\
\hline
\end{tabular}

Charpy impact tests were performed on standard Charpy V-notch specimens (size: $10 \times 10 \times 55 \mathrm{~mm}$, orientation: transverse-longitudinal) at $-30^{\circ} \mathrm{C}$ by Amsler RKP 450 impact tester of $450 \mathrm{~J}$ capacity. Optical microscopy (Olympus BX51) was used for metallographic observations. The bainite microstructure was also investigated by scanning electron microscopy (SEM, EVO 50) equipped with energy dispersive analysis (EDS).

\section{Results and discussion}

Microstructure and Impact Toughness. The X80 pipeline steels microstructures were characteristics of polygonal ferrite (PF), quasi-polygonal ferrite (QF) and granular bainite (GB), and while a certain proportion of MA constituent, as shown in Figure 1. These microstructures characteristic contains a large amount of dislocations, which causes significant strengthening and toughness effect. Most of the steels satisfy the strength and toughness requirement, and some impact toughness was over standard $100 \mathrm{~J}$ or more.

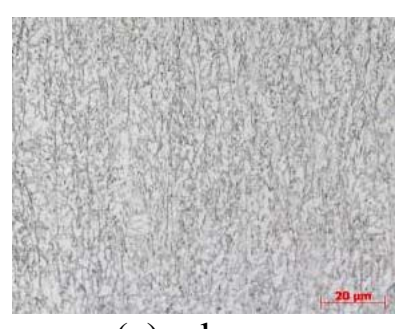

(a) edge

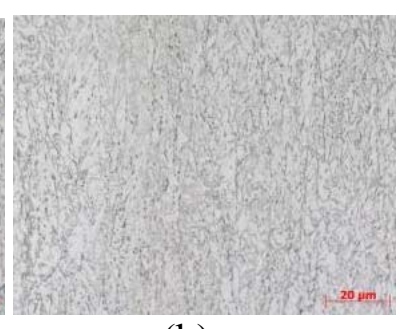

(b) core

Fig. 1 Microstructure of X80 pipeline steel

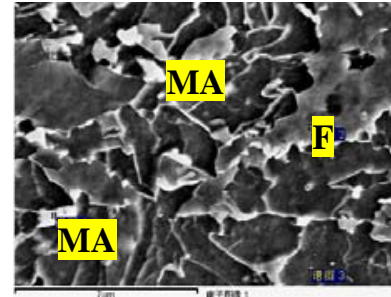

(a) edge

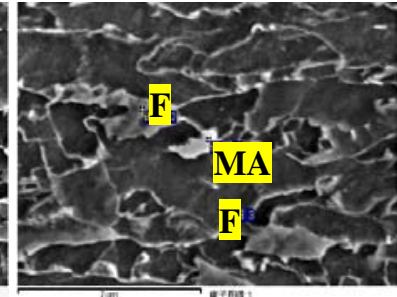

(b) core
Fig. 2 MA constituents in X80 pipeline steel

Table 2 Chemical composition of MA constituents in X80 pipeline steel, wt $\%$

\begin{tabular}{lcccc}
\hline & $\mathrm{Cr}$ & $\mathrm{Mn}$ & $\mathrm{Ni}$ & $\mathrm{Cu}$ \\
\hline Fig.2 (a) MA & 0.18 & 1.96 & 0.34 & 0.38 \\
Fig.2 (a) MA & 0.21 & 1.71 & 0.23 & 0.30 \\
Fig.2 (a) F & 0.16 & 1.72 & 0.14 & 0.15 \\
Fig.2 (b) MA & 0.19 & 1.88 & 0.34 & 0.27 \\
Fig.2 (b) F & 0.20 & 1.93 & 0.25 & 0.18 \\
Fig.2 (b) F & 0.21 & 2.01 & 0.26 & 0.21 \\
\hline
\end{tabular}

However, some samples toughness was instability. The result shows that there was no significant difference in organizational characteristics, besides MA constituent content more then the others. The SEM analysis showed that both edge and core area were located a certain percentage of MA constituents, the typical structure is shown in Figure 2. It has been shown that [4], MA constituent could produce an effect on impact toughness. Specially, MA constituent distributed at the grain boundaries (GBs) independently, the impact toughness could be reduced significantly. Also, this affection was increased with increasing MA constituent's quantity and coarse size. However, there was almost no effect on impact toughness if MA constituent distributed in bainitic ferrite (BF) grain interiors. On the other hands, MA constituent also reduced the impact toughness in GB and QF grain interiors. This was more easily noticeable MA constituent could lead to toughness reduction in this study. Therefore, it should be focus on reducing the content and size of MA constituent in order to get an excellent impact toughness.

The EDS analysis showed that, MA constituents composed mainly of $\mathrm{Cr}, \mathrm{Mn}, \mathrm{Ni}$ and $\mathrm{Cu}$. Comparison of $\mathrm{PF} / \mathrm{QF}$ with MA constituent of the composition suggested that $\mathrm{Ni}$ and $\mathrm{Cu}$ was tend to distribute in MA constituent, as shown in Table 2. In another words, there was segregation 
phenomenon in MA constituent such as $\mathrm{Ni}$ and $\mathrm{Cu}$, which determined that the composition of $\mathrm{Ni}$ and $\mathrm{Cu}$ may induce promotion MA constituent formation.

Component and Impact Toughness. To further study the different elements content on impact toughness in X80 pipeline steel, production composition and mechanical properties has been analyzed, the statistical analysis of fitting the results are shown in Figure 3.

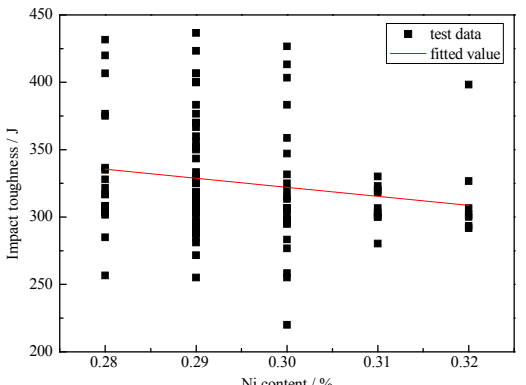

(a) $\mathrm{Ni}$

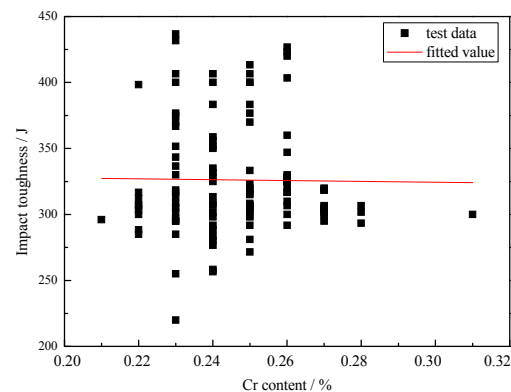

(d) $\mathrm{Cr}$

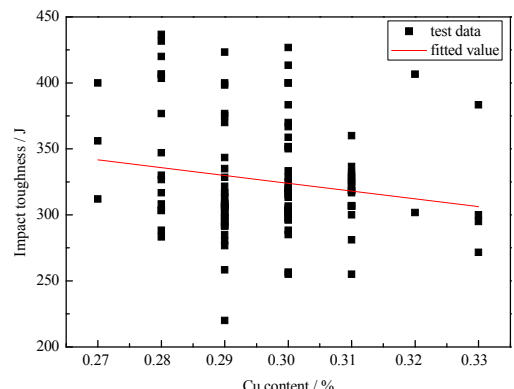

(b) $\mathrm{Cu}$

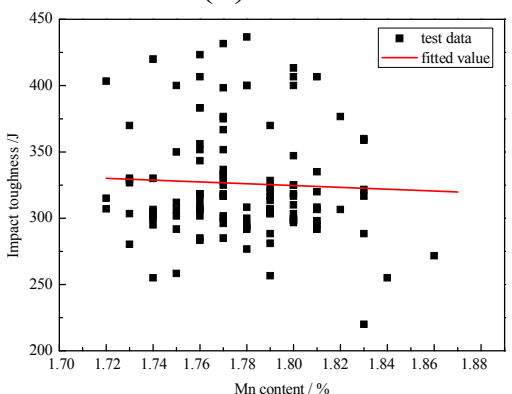

(e) $\mathrm{Mn}$

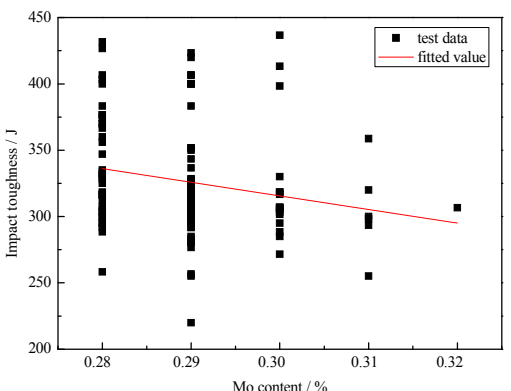

(c) Mo

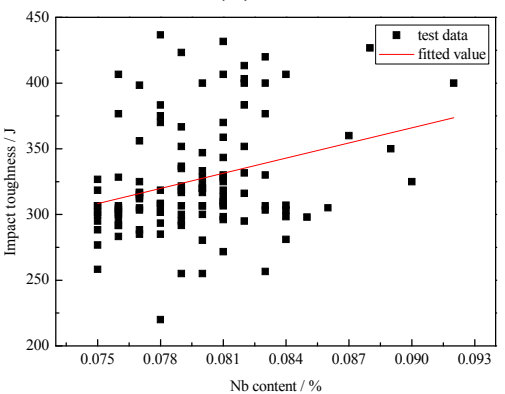

(f) $\mathrm{Nb}$

Fig. 3 Effect of alloy on impact toughness in X80 pipeline steel

Statistical analysis of property and alloying content suggests that the alloying elements can be divided into the following three categories. First, it reduced the impact toughness, such as $\mathrm{Cu}, \mathrm{Ni}$ and Mo alloys. Fitting results show that, $\mathrm{Cu}$ content increased from $0.27 \%$ to $0.33 \%$, the impact toughness reduced $36 \mathrm{~J}$, Ni content increased from $0.28 \%$ to $0.32 \%$, the impact toughness decreases $27 \mathrm{~J}$, Mo content increased from $0.28 \%$ to $0.32 \%$ the impact toughness reduced $41 \mathrm{~J}$, but these alloying element is not significantly affected on strength. The second, there was almost no effect on impact toughness, such as $\mathrm{Cr}$ and $\mathrm{Mn}$. Analysis results shown $\mathrm{Cr}$ content increased from $0.21 \%$ to $0.31 \%$, the impact toughness decreased only $3 \mathrm{~J}$, and Mn content increased from $1.72 \%$ to $1.86 \%$, impact toughness decreased $11 \mathrm{~J}$. The third, both improve the strength and impact toughness in X80 pipeline steel, such as $\mathrm{Nb}$ and $\mathrm{Ti}$ alloys. It shown that, $\mathrm{Nb}$ content increased from $0.075 \%$ to $0.092 \%$, the impact toughness increased $65 \mathrm{~J}$, the yield strength and tensile strength increases $14 \mathrm{MPa}$ and $17 \mathrm{MPa}$ separately, so as Ti content.

Effect of alloying elements. In the present study, the effect of the microstructure, composition and impact toughness statistics have been investigated and the results can be summarized as follows. The alloying elements such as $\mathrm{Ni}, \mathrm{Cu}$, Mo and et al. is employed in X80 pipeline steels, aim at obtain the QF and GB microstructure. But it promotes MA constituent transformation, and this result in the impact toughness reduction in X80 pipeline.

It has been reported [5] that $\mathrm{Ni}$ element is both benefit for improving the strength and toughness, especially for impact toughness at low temperature. This is attributed to Ni element solid solution reduces the dislocation motion frictional resistance, and also increases the stacking fault energy at low temperature. Nonetheless, $\mathrm{Ni}$ element is also effective to stabilize the austenite, and decrease the Ms temperature. At TMCP process conditions, if Ni element rich in micro-area because of the high content of Ni alloying additions, that will induce austenite stability increased in the region, while it will eventually change into MA group undesirable. Therefore, much more MA consistent results in the toughness instable. Moreover, $\mathrm{Cu}$ alloying is also austenite stabilizing element. Comparison of $\mathrm{Cu}$ element with $\mathrm{Ni}$ alloying suggests that they have the similar effect on microstructure. 
Mo element with significant inhibition of eutectoid ferrite effect [6]. The PF transformation will be inhibited and the QP and GB microstructure is obtained as to add the right amount of Mo alloying. However, it is able to demonstrate that much more Mo element addition causes MA consistent increased in this study. And so impact toughness decreased with increasing the Mo content.

The microstructure and impact toughness statistical analysis shows that MA consistent increased with increasing the $\mathrm{Ni}, \mathrm{Cu}$ and Mo alloying content and this make further efforts to induce the impact toughness deteriorated. And further work will be directed to elucidating the right content of the Mo, $\mathrm{Ni}$, and $\mathrm{Cu}$ additions, and also the relationship between different alloying elements such as $\mathrm{Cr}$ and $\mathrm{Mo}$. And reasonable design scheme of the X80 pipeline steels alloying elements remain objects of future investigation.

\section{Conclusions}

In the present study, the effect of alloys element content on microstructure and impact toughness in X80 pipeline steels have been investigated and the results can be summarized as follows: the alloying elements in X80 pipeline steel can be divided into three categories in this condition. First, Ni, $\mathrm{Cu}$ and Mo alloy, it promotes the MA constituents transformation, and leading the impact toughness decreases. Second, $\mathrm{Cr}$ and $\mathrm{Mn}$ alloy, which have no significant effect on impact toughness. And the third, $\mathrm{Nb}$ and Ti micro-alloying, which is particularly improving the impact toughness in pipeline steel.

The microstructure and impact toughness statistical analysis shows that MA consistent increased with increasing the $\mathrm{Ni}, \mathrm{Cu}$ and Mo alloying content and this make further efforts to induce the impact toughness deteriorated. So the $\mathrm{Ni}, \mathrm{Cu}$ and Mo alloying elements content should be limited, but increasing the $\mathrm{Nb}$ alloying content is benefit for increasing the impact toughness.

\section{Acknowledgements}

This work was financially supported by the Chinese Ministry of Education (109048) and the Program for New Century Excellent Talents of Ministry of Education (NCET-11-0077). The authors are grateful for these supports.

\section{References}

[1] H L Liu, C J Liu and M F Jiang. Materials \& Design Vol. 33 (2012), p. 306

[2] P O Maruschak, I M Danyliuk and R T Bishchak. Open Engineering Vol. 4(2014), p. 408

[3] B Hwang, G K Yang and S Lee. Metallurgical \& Materials Transactions A Vol. 36(2005), p. :371

[4] F Xu, J H Kong and J Q Xu. Petroleum Instruments Vol. 1(2015), p. 32 (in Chinese)

[5] J Kong, L Zhen and B Guo. Materials \& Design Vol. 25(2014), p. 723

[6] S Han, C X Wang and J Pei. Hot Working Technology Vol. 41(2012), p. 75 (in Chinese) 